ARTICLE

Received 18 Jan 2017 | Accepted 19 Jun 2017 | Published 1 Aug 2017

DOl: $10.1057 /$ palcomms.2017.71

\title{
Childhood experience of nature influences the willingness to coexist with biodiversity in cities
}

Tetsuro Hosaka ${ }^{1}$, Koun Sugimoto ${ }^{1}$ and Shinya Numata ${ }^{1}$

\begin{abstract}
Although efforts to promote biodiversity in cities around the world have increased, many wild animals (including vertebrates and invertebrates) comprising "urban biodiversity" are unpopular or often regarded as a nuisance by the general public, particularly by those city residents who have had little experience with nature. We conducted a questionnaire survey with 1030 urban residents in Japan to assess their likeability (like and dislike) towards 29 wild animals, and their willingness to have these animals in their neighbourhoods, and examined the effects of childhood experience of nature and socio-demographic factors on these attitudes. In general, people liked smaller birds and mammals, and some insects, but were only willing to have birds and insects near their homes. Females liked birds and mammals but disliked insects and unfavourable animals more than males. Older people expressed willingness to coexist with insects and birds more than younger people. However, childhood experience with nature, particularly collecting insects and plants, was a more important factor than socio-demographics for positive attitudes towards wild animals. Therefore, even though urban residents were unwilling to coexist with many animals, their attitudes can become more positive through increased interaction with wild animals and plants. Biodiversity conservation initiatives in cities should place greater emphasis on providing children with more interaction with biodiversity.
\end{abstract}

\footnotetext{
${ }^{1}$ Graduate School of Urban Environmental Sciences, Tokyo Metropolitan University, Hachioji, Japan Correspondence: (e-mail: tetsurau@yahoo.co.jp)
} 


\section{Introduction}

fforts towards the conservation, rehabilitation and enhancement of biodiversity in urban areas have increased globally as cities have expanded in size and population (Miller and Hobbs, 2002; Dearborn and Kark, 2010; Shwartz et al., 2014) Such efforts include the construction of new, diverse green spaces (de Oliveira et al., 2011), creation of ecological networks connecting urban green spaces (de Oliveira et al., 2011; Fábos and Ryan, 2004), and promotion of species richness and structural heterogeneity in urban parks (Skandrani and Prévot, 2015), and even in domestic gardens (Goddard et al., 2010) and on rooftops (Williams et al., 2014). Biodiversity has become a key element in urban landscape design and the management efforts of national and local governments, private companies and citizen groups (CBD, 2012).

However, many wild animals (including vertebrates and invertebrates) that comprise "urban biodiversity" are unpopular with, or not well accepted by, the general public. Some previous studies have shown a wide range of public affective attitudes towards wild animals (Kellert, 1980; Bjerke and Østdahl, 2004; Schlegel and Rupf, 2010). These studies suggest that people are keen on aesthetic animals such as butterflies and birds. Affective attitudes towards mammals are more variable among species and people. On the other hand, many invertebrates are perceived as pests, even when they are not harmful (Baldwin et al., 2008). Besides well-known pests (for example, mosquito,

rat and cockroach), animals that people most disliked were wasps, bats and skunk in US (Kellert, 1980), snail, wasp/ bee and beetle in Norway (Bjerke and Østdahl, 2004) and field cricket, toads and ground beetle in Switzerland (Schlegel and Rupf, 2010). Such affective attitudes can have greater effect on public support than cognitive considerations for biodiversity conservation (Martín-López et al., 2007). To ensure greater public support for biodiversity conservation, it is critical to understand public attitudes (for example, likeability and acceptance) towards wild animals and the factors that influence those attitudes.

This information is particularly important in urban areas, where diverse stakeholders with differing values and attitudes live and work together (Miller and Hobbs, 2002). Public affective attitudes towards wild animals can differ among different populations in gender, age, education and income (Kellert, 1993, 1996; Bjerke and Østdahl, 2004; Schlegel and Rupf, 2010; Zhang et al., 2014; Soga et al., 2016). These previous studies consistently showed that males are more positive towards wild animals, particularly for unpopular animals such as invertebrates, while females are more positive towards aesthetic and popular animals such as pets. The importance of observing birds and insects as motives for taking walks increased with age in Norwary (Bjerke and Østdahl, 2004), while older people expressed less interest and affection towards animals than younger people in USA (Kellert, 1996).

Besides these socio-demographic factors, personal experiences can strongly shape attitudes towards wild animals. Childhood experiences in nature, including direct or firsthand experiences of nature such as fishing, hunting, insect catching, plant collecting, hiking and camping (Lekies and Brensinger, 2015; Soga et al., 2016) and vicarious or secondhand experiences of nature such as those through TV, books and websites (Eagles and Muffitt, 1990; Soga et al., 2016), are known to promote one's environmental preferences, competencies, and concerns (Bixler and Floyd, 1997; Chawla, 1999; Bixler et al., 2002; Wells and Lekies, 2006; Chawla and Derr, 2012); the former type of experiences often have greater impacts than the latter (Chawla, 1999; Chawla and Derr, 2012). For example, middle and high school students who reported to have played in wild environments showed more positive perceptions towards natural environments, outdoor recreation activities and future outdoor occupations (Bixler et al., 2002). Although studies on the relationships between childhood nature experience and attitudes towards wild animals are limited, recent children studies reported that children who played in nature frequently liked wild animals and wanted to conserve them more than those who played infrequently in China (Zhang et al., 2014) and Japan (Soga et al., 2016). These results are consistent with a hypothesis that biophilia (love of life or living systems), regardless whether it is innate (Kellert and Wilson, 1993) or not (Simaika and Samways, 2010), is strongly triggered by contact with nature in childhood (Nabhan and St. Antoine, 1993). Children survey, however, is weak in demonstrating causal relationships between nature experience and attitude; children's participation in nature activities might be consequences of their interests in animals rather than causes, and its effects on their attitudes for a longer time period are unclear. Therefore, a survey on the relationship between adults' attitudes towards animals and their childhood nature experiences will provide stronger evidence for the effects of childhood experience in a life span perspective. Moreover, the types of nature-related activity in childhood that more effectively enhance affective attitudes towards wild animals have not been well studied. Since childhood nature experience might have been declining due to urbanization and lifestyle changes (Miller, 2005; Soga and Gaston, 2016), understanding the effects of childhood nature experience on affective attitudes of adults towards wild animals is an urgent issue for biodiversity conservation.

Additionally, the species that people express most like for might not be the same as those that they are willing to coexist with in an urban setting. For example, although more than three quarters of the Swedish population professed to like bears and wolves, their support for conservation programs declined when people's encounters with these animals increased (Eriksson et al., 2015). If there is a gap between affective attitude towards, and willingness to coexist with, a certain species, enhancement of affective attitude towards biodiversity alone does not guarantee wider public support for urban biodiversity conservation.

In summary, it is important to understand affective attitudes of urban residents towards wild animals and factors affecting the attitudes. Based on the previous studies above, we hypothesized that childhood nature experience will positively influence affective attitudes, that is, likeability and willingness for coexistence in this study, towards wild animals among adult urban residents. To test this hypothesis, we assessed the frequency of nature-related activities in childhood (Experience), likeability (that is, like or dislike) towards 29 wild animals (Likeability), and willingness to coexist with these animals (Willingness) for 1030 urban residents in Japan. We also included sociodemographic factors, that is, sex, age, having children or no children and income, in one model to evaluate the effects of childhood nature experience after controlling these factors. Specifically, we addressed the following questions:

(1) What experiences do urban residents report having in childhood?

(2) Which wild animals do urban people like and wish to coexist with in cities?

(3) Is there a relationship between likeability for certain animals and willingness to coexist with them?

(4) To what extent does experience predict likeability and willingness?

(5) What nature-related activity in childhood is most strongly associated with encouraging likeability? 


\section{Methods}

Study site. Biodiversity conservation has been increasingly highlighted also in Japan. Following the adoption of the Nagoya Protocol of the Convention on Biological Diversity in 2010, 46 municipalities including 13 designated cities with more than 500,000 population (for example, Nagoya city, Yokohama city and Kobe city) has established a local biodiversity act as of November 2016 (MOE, 2016).

Tokyo and its surrounding area including Kanagawa, Chiba and Saitama prefectures is home to the world's largest urban population (38 million inhabitants) (UN, 2014). Although the total area of green space in Tokyo has decreased continuously since the 1960s through attritions in forested and agricultural land, the rate of decline has been slowing through time (Hosaka and Numata, 2016). Conversely, the area of urban park land has increased continuously. The proportion of green spaces in the city center is $19.8 \%$ in 2013 and slightly increasing (Tokyo Metropolitan Government, 2014). The Tokyo Metropolitan Government recently established a new strategy for urban greening using biodiversity conservation as a central concept to promote quality of green spaces as habitats for wild plants and animals (Tokyo Metropolitan Government, 2012).

On the other hand, the number of consultations about wasps and nuisance wild animals (for example, snakes and civets) are increasing in Tokyo (Hosaka and Numata, 2016). Although it is not known whether the increase of consultation is due to an increase of animal abundance or due to a decrease of human tolerance, the rapid increase of wasp consultations is common across large cities in Japan (Nakamura, 2007). Since these nuisance animals can also increase with increasing green spaces (Azmy et al., 2016), an understanding of public attitudes towards a range of wild animals is important to obtain public supports for conservation activities.

Questionnaire. A web-based questionnaire survey was conducted in January 2016 via an internet research company (Macromill, Inc., Tokyo, Japan). We did not seek approval by an institutional review board (ethics committee) for the present study with following reasons; (1) the data were appropriately collected and managed by the research company which strictly follows the privacy policy and research guideline by European Society for Opinion and Marketing Research and Japan Marketing Research Association, holding the "Privacy Mark" certification of the Japan Information Processing and Development Center, (2) the participants provided their informed consent to participate in this study via online before the survey, (3) the data are totally anonymized when we obtain the data, and will have no potential risks to individuals or individual privacy.

The questionnaire was answered by 1030 residents (aged 20-69) in Tokyo and its surrounding area, Chiba, Saitama and Kanagawa prefectures. We collected equal numbers of responses for each sex and age group (103 males aged 20-29 years, 103 females aged 20-29 years, ..., 103 females aged 60-69 years). The company distributed the questionnaire to all the monitors (18,996 individuals) who met the criteria of this study (aged 20-69 and living in the area mentioned above), and then collected responses up to the number (103) that we designated for each sex and age category. The respondents were similar in most characteristics to those participating in other nationwide surveys, such as public opinion polls by Japan Government, including with respect to frequency of involvement in outdoor activities, and environmental concerns (although not for frequency of Internet use) (Macromill, 2013).

To quantify Experience, we recorded the frequency of participation in five nature-related activities: insect catching, fishing, collecting wild flowers and fruits, tree climbing, and swimming in rivers/the ocean during childhood ( $\leq 12$ years old). These activities have been common among Japanese children for at least the last 70 years (Kamihogi, 2009). Respondents replied on a 5-point scale ranging from 1 (never) to 5 (very often). Although the retrospective self-report approach has a limitation in quantifying actual frequency of activities, we adopted this method following previous studies (for example, Bixler et al., 2002; Wells and Lekies, 2006) due to the ease of answering for respondents and the difficulty in collecting reliable objective data.

To quantify Likeability, we asked whether respondents liked or disliked 29 wild animals based on a 5-point scale ranging from 1 (dislike) to 5 (like), with three indicating a neutral response. The 29 animals included 14 types of mammal, 9 insects, 4 birds, 1 snake and 1 frog. These animals are either common in urban areas of Japan or are well-known to the public, and encompass a range across the likeability spectrum (Sawaki and Kamihogi, 1995; Sonoda and Kuramoto, 2004). We also asked whether respondents were familiar with each animal, regardless of whether he/she had actually seen it before. When the respondents were not familiar with an animal, they were not asked to respond about their affective attitudes towards it.

To quantify Willingness, we asked the respondents to select the most desirable habitat for each of the 29 animals from among the following four locations at different distances from their homes: (1) nowhere, (2) forests and parks distant from one's home, (3) green spaces near one's home (within walking distance), or (4) anywhere, including one's own garden. Again, respondents were not asked to answer these questions if they were unfamiliar with the animal.

Before the main survey, we conducted preliminary survey to around 20 students in our university to check if the respondents correctly understand the questionnaire items. The questionnaire items are shown in Supplementary Table S1.
Analysis. To answer the first question, we calculated the percentage of respondents that scored each activity based on the frequency they were involved in childhood.

To answer the second question, we calculated the mean Likeability and Willingness scores for each animal. For the Willingness scores, we combined the answers to (1) and (2) to give score " 0 ", and those of (3) and (4) to give score " 1 ". This enabled evaluation of the percentage of respondents who were willing to have the animal near their home, by calculating the mean scores for each animal (for example, a mean score of 0.4 for a specific animal indicated that $40 \%$ of respondents were willing to have the animal near their home). We performed exploratory factor analysis to group the animals based on the Likeability scores. The optimum number of groups was determined with a parallel test and Minimum Average Partial (MAP) test using Very Simple Structure function, and we performed maximum likelihood factor analysis using promax rotation (Revell, 2016).

For the third question, we examined the correlation between the mean scores of Likeability and Willingness for each animal using Pearson correlation coefficients.

For the fourth question, we calculated the mean scores of Likeability and Willingness, for each respondent and for each animal group, determined by the factor analysis. We also calculated the mean score of Experience for each respondent. The Cronbach's $\alpha$-value for the five activities was 0.85 , which allowed these items to be combined into additive indices. Then, we constructed multiple linear regression models using the mean score of Likeability or Willingness as a response variable, and the mean scores of Experience and four socio-demographic factors as explanatory variables. The socio-demographic factors included sex $(0=$ male, $1=$ female $)$, age, having children $(0=$ do not have, $1=$ have $)$, and annual household income. These socio-demographic parameters have been used often to assess public attitudes towards wildlife (Kansky and Knight, 2014). The data for the explanatory variables were standardized before the analysis to enable comparison of the size of the effect among variables based on the standardized coefficients.

For the fifth question, we constructed a linear regression model using the mean score of Likeability towards each animal group as a response variable, and the frequencies of participation in each nature-related activity as explanatory variables. Since our preliminary analysis indicated that sex and age had significant effects on the scores of activities, we included these variables in the model to control for their effects on the frequencies of the activities. Since the scores for each activities were moderately correlated each other $(r=0.37-0.65$ : mean $=0.47)$, we adopted a model-averaging approach for model selection to deal with the effect of collinearity on parameter estimates (Freckleton, 2011). A set of models with all possible combinations of explanatory variables was ranked based on the Akaike information criterion (AIC). Then, we calculated the weighted average of each estimated parameter based on the models within four AIC value from the best model. The significance of the parameter estimate was assessed by testing whether it was significantly different from zero based on the weighted average and standard error All analyses were performed with R (ver. 3.3.1; R Development Core Team, Vienna, Australia), and the R packages psych (Revell, 2016) for factor analysis and MuMIn (Baltoń, 2015) for model averaging.

\section{Results}

What experiences do urban residents report having in childhood? All five of the nature-related activities were popular among urban residents; over one third of the respondents replied "often" or "very often" with respect to their participation in each activity during childhood (Fig. 1). Insect catching was the most popular activity (54\% of respondents responded "often" or "very often"),

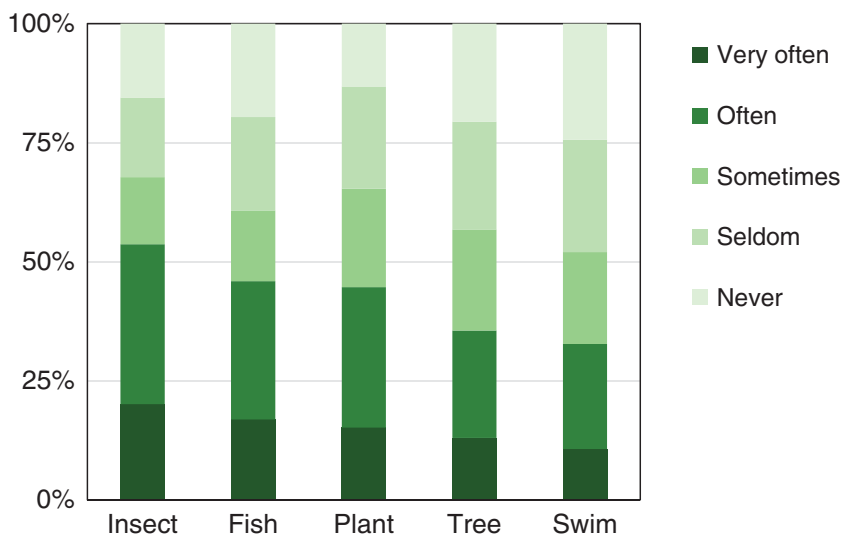

Figure 1 | Frequency of involvement in nature-related activities: insect catching (Insect), fishing (Fish), collecting wild flowers and fruits (Plant), tree climbing (Tree), swimming in rivers/the ocean (Swim). 
followed by fishing (46\%), plant collecting (45\%), tree climbing $(36 \%)$ and swimming in rivers $(33 \%)$.

Which wild animals do urban people like and wish to coexist with in cities? Among the 29 animals, fireflies were the most liked (mean score: 3.78), followed by bush warblers (3.74) and squirrels (3.73) (Fig. 2). Hornets were the most disliked (1.72), followed by moths (2.02) and snakes (2.16). In total, 16 of the 29 animals had a mean Likeability score $>3.00$. Respondents were most willing to coexist with three small birds: sparrows (0.78), bush warblers (0.77) and swallows (0.71), while they were least willing to live near bears $(0.02)$, boars $(0.03)$ and hornets (0.06). Only ten animals had a mean Willingness score $>0.5$.

Both parallel analysis and the MAP test indicated that the 29 animals could be classified into five groups based on Likeability score. The five groups suggested by factor analysis were clearly distinctive in taxon: seven insects, eight mammals, three birds and four large mammals, with the exception of one group that consisted of various animals that had lower Likeability scores (Table 1). We named these groups "Insects", "Mammals", "Birds", "Large Mammals" and "Unfavourable Animals", respectively. The mean scores for Likeability were highest for Birds, followed by Mammals, Insects, Large Mammals and Unfavourable Animals (Table 2).

Is there a relationship between likeability for certain animals and willingness to coexist with them? The mean Willingness score for each animal was significantly positively correlated with the mean Likeability score $(r=0.57, d f=27, P<0.01$; Fig. 2). However, as mentioned above, the number of animals that people wanted to coexist with was smaller than the number of animals that people liked. The six animals that had $>3.0$ Likeability scores but $<0.5$ Willingness scores were all mammals.

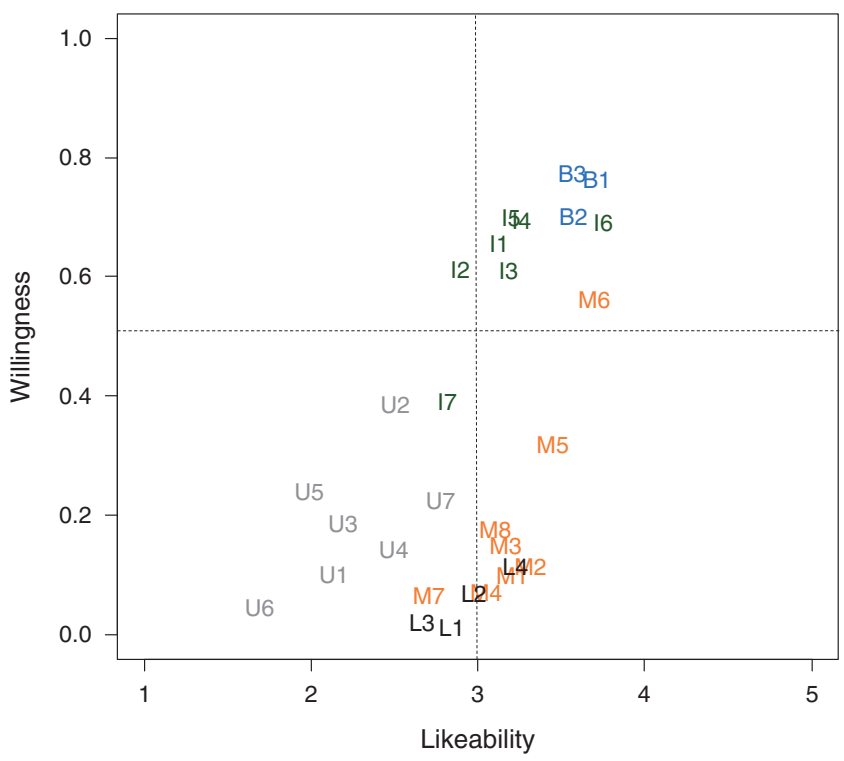

Figure 2 | Relationship between the mean scores of likeability towards, and willingness to coexist with, Insects (green letters), Mammals (orange), Unfavourable animals (grey), Birds (blue) and Large mammals (black). Vertical horizontal broken lines indicate scores of $\mathbf{3 . 0}$ (neutral) and 0.5 (50\% of respondents are willing to coexist with the animal), respectively. The codes for each animal are shown in Table 1.
Table 1 | Factor loadings $(\geq 0.35)$ for each animal, and grouping of animals based on the likeability scores

Code Factor1 Factor2 Factor3 Factor4 Factor5

\begin{tabular}{|c|c|c|c|c|c|c|}
\hline \multicolumn{7}{|l|}{ Insects } \\
\hline Bell cricket & 11 & 0.94 & - & - & - & - \\
\hline Cicada & 12 & 0.90 & - & - & - & - \\
\hline $\begin{array}{l}\text { Rhinoceros } \\
\text { beetle }\end{array}$ & 13 & 0.89 & - & - & - & - \\
\hline Dragonfly & 14 & 0.87 & - & - & - & - \\
\hline Butterfly & 15 & 0.81 & - & - & - & - \\
\hline Firefly & 16 & 0.61 & - & - & - & - \\
\hline Honeybee & 17 & 0.47 & - & 0.37 & - & - \\
\hline \multicolumn{7}{|l|}{ Mammals } \\
\hline Raccoon & M1 & - & 0.94 & - & - & - \\
\hline Fox & M2 & - & 0.93 & - & - & - \\
\hline Raccoon dog & M3 & - & 0.85 & - & - & - \\
\hline Badger & M4 & - & 0.77 & - & - & - \\
\hline Hare & M5 & - & 0.75 & - & - & - \\
\hline Squirrel & M6 & - & 0.50 & - & 0.42 & - \\
\hline Civet & M7 & - & 0.44 & - & - & - \\
\hline Flying squirrel & M8 & - & 0.39 & 0.35 & - & - \\
\hline \multicolumn{7}{|c|}{ Unfavourable animals } \\
\hline Snake & U1 & - & - & 0.90 & - & - \\
\hline Frog & U2 & - & - & 0.70 & - & - \\
\hline Crow & U3 & - & - & 0.66 & - & - \\
\hline Bat & U4 & - & - & 0.66 & - & - \\
\hline Moth & U5 & - & - & 0.61 & - & - \\
\hline Hornet & U6 & - & - & 0.52 & - & - \\
\hline Mole & U7 & - & - & 0.43 & - & - \\
\hline \multicolumn{7}{|l|}{ Birds } \\
\hline Bush warbler & B1 & - & - & - & 0.91 & - \\
\hline Swallow & B2 & - & - & - & 0.83 & - \\
\hline Sparrow & B3 & - & - & - & 0.77 & - \\
\hline \multicolumn{7}{|l|}{ Large mammals } \\
\hline Bear & L1 & - & - & - & - & 0.65 \\
\hline Monkey & $\mathrm{L} 2$ & - & - & - & - & 0.65 \\
\hline Boar & L3 & - & - & - & - & 0.63 \\
\hline Deer & L4 & - & - & - & - & 0.54 \\
\hline
\end{tabular}

To what extent do experience predict likeability and willingness? The Experience scores were significantly correlated with the Likeability scores for all animal groups. Experience was the most important factor for Birds, Large Mammals, Unfavourable Animals, and all animals combined, and was the second most important factor for both Mammals and Insects (Table 2). Similarly, Experience was the most, or second most, important factor for predicting the Willingness scores for all the animal groups.

Among the socio-demographic factors, gender, age, having a child or not had significant effects on Likeability and/or Willingness. Females liked Birds and Mammals but disliked Insects and Unfavourable Animals more than males. Older people liked Birds and Insects, but disliked Mammals and Large Mammals more than younger people. Those having a child disliked Insects and Unfavourable Animals more than those having no child. However, none of the socio-demographic factors were significant for Likeability scores of all animals combined. Gender was not significant for Willingness except for Insects. Older people were more willing to have Birds and Insects, but less willing to have Mammals, near their home. Only age was significant for Willingness scores of all animals combined.

The model fitness $\left(R^{2}\right)$, however, was generally low for both Likeability (0.05-0.24) and Willingness (0.03-0.14). 


\begin{tabular}{|c|c|c|c|c|c|c|c|}
\hline \multicolumn{8}{|l|}{ Likeability } \\
\hline Birds & 3.64 & $0.24^{\star \star \star}$ & $0.07^{\star}$ & $0.08^{\star \star}$ & -0.04 & -0.03 & 0.08 \\
\hline Mammals & 3.24 & $0.17^{\star \star \star}$ & $0.06^{\star}$ & $-0.18^{\star \star \star}$ & 0.00 & 0.01 & 0.10 \\
\hline Unfavourable animals & 2.28 & $0.16^{\star \star \star}$ & $-0.11^{\star \star \star}$ & -0.01 & $-0.08^{\star \star}$ & 0.01 & 0.08 \\
\hline All & 3.00 & $0.20^{\star \star \star}$ & -0.04 & 0.02 & -0.04 & 0.01 & 0.11 \\
\hline \multicolumn{8}{|l|}{ Willingness } \\
\hline Birds & 0.75 & $0.04^{\star \star}$ & 0.03 & $0.04^{\star \star}$ & 0.00 & 0.00 & 0.03 \\
\hline Mammals & 0.21 & $0.04^{\star \star \star}$ & 0.00 & $-0.03^{\star \star}$ & -0.01 & 0.00 & 0.04 \\
\hline
\end{tabular}

What nature-related activity in childhood is most strongly associated with encouraging likeability? Among the naturerelated activities in childhood, plant collecting was the most important for Likeability towards Birds, Mammals, and Large Mammals, and insect catching was the most important for Likeability towards Insects and Unfavourable Animals (Table 3). For all animals combined, insect catching was the most important factor for Likeability, followed by plant collecting.

\section{Discussion}

Likeability towards and willingness to coexist with wild animals. The respondents in our study liked smaller birds and mammals, and several insects, while they disliked hornets, snakes and moths. Appreciation of butterflies and birds, and aversion to snakes, is common globally (Kellert, 1980; Bjerke et al., 2001; Bjerke and Østdahl, 2004; Schlegel and Rupf, 2010; Zhang et al., 2014). In western countries, people often have negative perceptions towards insects other than butterflies (Kellert, 1993; Bjerke and Østdahl, 2004; Schlegel and Rupf, 2010). In contrast, respondents also liked several other insects, such as fireflies, rhinoceros beetles and bell crickets in our study. Additionally, insect catching was the most popular childhood nature activity among the respondents, although this is not the case in other countries (for example, Bjerke and Østdahl, 2004). Our results reflect the unique insect-appreciating culture that exists in Japan (Hogue, 1987; Kawahara, 2007; Hosaka et al., 2016).

Although likeability towards animals was significantly correlated with willingness to coexist with those animals, the respondents were unwilling to have wild animals near to their home, other than favourable birds and insects. In particular, they were unwilling to coexist with mammals, even though they did not dislike mammals. This is probably due to concern that damage and disease could be caused by mammals (Soulsbury and White, 2015). This implies that a simple enhancement of public likeability towards animals will not always lead to greater willingness for the animals living nearby residential areas when the animals can cause problems.

However, actual problems caused by urban wild animals are minor in most cases, and there is often a large gap between actual problems and perceived problem (Dickman, 2010). Effective public information campaigns and educational programs on some unfavourable animals, which include close observation of the animals and education about their importance in ecosystems, endangered status and actual risks, successfully changed attitudes towards bobcats (Hudenko et al., 2010), crocodiles (van der Ploeg et al., 2011), snakes (Ballouard et al., 2012) and tarantulas (Kawahara and Pyle, 2013). Such education is very important to change the negative attitudes towards unfavourable animals.

Importance of childhood experience with nature. Childhood experience with nature was more important than sociodemographic factors in terms of influencing likeability towards, and willingness to coexist with, wild animals. This is consistent with previous studies that showed positive effects of interaction with nature on attitudes towards biodiversity and natural ecosystems among schoolchildren in the USA (Eagles and Muffitt, 1990; Bixler et al., 2002), Norway (Bjerke and Østdahl, 2004); China (Zhang et al., 2014) and Japan (Soga et al., 2016). Our results provide further evidence that the positive effects of childhood experience with nature on attitudes towards wild animals last into adulthood. In other words, our results support the hypothesis that biophilia is triggered (or formed) by experience with nature in childhood.

Among the various activities, our model-averaging analysis indicated that catching insects and collecting wild flowers and fruits had a greater effect on likeability towards animals than tree climbing and swimming in rivers/the sea. The minor importance of fishing might be due to the lack of aquatic animals in the list of animals surveyed (for example, fish). Collecting and foraging of natural materials (for example, rocks, plants and insects) are fundamental nature activities in childhood, and promote one's psychological connection to nature (Lekies and Beery, 2013) and better cognition about biodiversity (Chipeniuk, 1995). Since collecting requires knowledge and skills for searching, collecting, handling and identifying the items (Lekies and Beery, 2013), it would effectively promote children's understanding and affective attitudes towards living organisms and natural world. Our results further emphasize that collecting experiences in childhood positively affect people's attitudes towards a wide range of animals. 
Table 3 | Standardized regression coefficients based on model averaging for nature-related activities to predict likeability scores towards each animal group

\begin{tabular}{|c|c|c|c|c|c|}
\hline & Insect catching & Fishing & Plant collecting & Tree climbing & Swimming in the river/sea \\
\hline$\overline{\text { Birds }}$ & $0.01^{\star}$ & 0.03 & $0.18^{\star \star \star}$ & -0.03 & 0.02 \\
\hline Mammals & 0.03 & 0.05 & $0.13^{\star \star \star}$ & 0.05 & 0.02 \\
\hline Insects & $0.30^{\star \star \star}$ & -0.01 & $0.08^{\star}$ & -0.02 & 0.01 \\
\hline Unfavourable animals & $0.11^{\star \star \star}$ & $0.07^{\star}$ & 0.01 & 0.01 & 0.02 \\
\hline All & $0.13^{\star \star \star}$ & 0.04 & $0.09^{\star \star \star}$ & 0.01 & 0.02 \\
\hline
\end{tabular}

These results suggest that childhood nature experiences have a vital role in shaping affective attitudes towards various types of wild animals. Therefore, it is essential to include strategies in conservation programs to provide children with opportunities and orientations to interact with nature such as collecting plants and animals. Such hands-on experiences can be available to children through free play, learning at nature centers and school summer camps (Chawla and Derr, 2012), and recreational and tourism events (Lemelin, 2013; Hosaka et al., 2016). However, collecting wild plants and animals are increasingly discouraged or prohibited in numerous areas, from national to urban parks, to support the "protection of nature" (Chipeniuk, 1995; Nomura, 2000). Collecting insects is generally viewed with disdain, and is strongly discouraged by formal prohibitions and social pressures in many advanced societies (New, 2013). However, our results suggest that a prohibition against collecting activities may prevent children from becoming familiar with wild animals and plants, and might reduce appreciation for biodiversity. We should carefully protect endangered species and vulnerable ecosystems from human impacts. At the same time, it would also be important to provide green spaces where children are free to collect common plants and insects.

Gender and age were important socio-demographic factors. Females had slightly more positive attitudes than males towards Birds and Mammals, but more negative attitudes towards Insects and Unfavourable Animals. This is consistent with previous studies reporting positive attitudes towards popular and aesthetic species (pets in particular) among females, while males had more positive attitudes towards less-preferred animals (Kellert, 1996; Bjerke and Østdahl, 2004). The inter-gender differences in likeability may reflect more humanistic (strong emotional attachment and "love" for aspects of nature) and negativistic (fear, aversion, alienation from nature) values of females and more ecologistic (systematic study of structure, function and relationship in nature) and naturalistic (direct experience and exploration of nature) values of males (Kellert, 1996). Such intergender differences in likeability, however, did not significantly affect differences in willingness to coexist with the animals, except for insects.

Older people had more positive attitudes towards Birds and Insects, and were more willing to coexist with wild animals than younger people. Interestingly, our previous study reported lower tolerance of older people towards problem-causing animals (for example, hornets and wild boars, (Hosaka et al., 2017). Previous studies also reported higher affective attitude towards birds and insects ((Bjerke and Østdahl, 2004) (but Kellert, 1996) but lower tolerance towards problem-causing mammals (Butler et al., 2003; Siemer et al., 2009; Sakurai et al., 2014) for older people. Therefore, older people had "dual characters"; on the one hand, they were more willing to coexist with aesthetic animals, but on the other hand, they would not tolerate problems caused by the animals, which probably reflects their utilitarian (practical and material exploitation of nature) and dominionistic (mastery, physical control, dominance of nature) values towards animals (Kellert, 1996). Such attitudes among older people may become more important for conservation programs in rapidly aging societies.

\section{Limitations}

First, our retrospective self-report approach is somewhat subjective. We did not ask actual frequency of their activities in childhood since it was not easy for them to accurately answer about their activities some 10-60 years ago. Therefore, more accurate interpretation of our result would be that people who thought frequently engaged in nature activities during childhood showed higher Likeability and Willingness towards wild animals than did those with little childhood nature experience.

Second, our question to measure the level of Willingness, "where do you think is the desirable place for the following animals to inhabit?", might lead some confusion or misunderstanding among respondents. We expected the respondents to answer the places where they want to have a certain animal, but respondents may answer the places where the animal should be; he/she may think forest animals should live in wilder areas even though he/she wants to see the animals nearby. However, a strong correlation between Likeability and Willingness scores implies that most respondents answered this question based on their preference rather than animals' preference. Also, all the students in our preliminary study successfully answered this question based on their preference. Therefore, our interpretation that their answer for this question reflected their willingness to have the animals nearby would be valid.

Third, it might be difficult to generalize our results on popular animals and childhood activities in a global context since they can vary among countries and cultures. As shown above, Japanese people like insects, probably more than people do in other countries, and insect catching is very popular among children in Japan. More studies on types of childhood nature experiences and affective attitudes towards animals, and their relationships should be examined in other countries and cultures.

Our models explained only a small amount of variance in Likeability and Willingness to coexist scores. Although it was not our objective to understand whole factors affecting the attitudes, inclusion of other variables such as education (Kellert, 1993), media exposure (Siemer et al., 2009) and beliefs (Inskip et al., 2016) may improve the model fitness.

\section{Conclusion}

Urban residents showed a range of attitudes towards wild animals, and were unwilling to coexist with most animals, except favourable birds and insects. Their attitudes, however, were strongly affected by their childhood experience with nature. Therefore, their attitudes may become more positive through 
increasing interaction with wild animals. Hence, not only creation of protected areas for rare native species, but also creation of green spaces for children to directly interact with animals and plants (irrespective of native or nonnative species), should be prioritized in cities. Effective orientation to encourage children to use such green spaces is equally important. At the same time, education about ecosystem functions and actual risk of unfavourable animals are important to obtain wider support for urban biodiversity conservation.

\section{References}

Azmy MM, Hosaka T and Numata S (2016) Responses of four hornet species to levels of urban greenness in Nagoya city, Japan: Implications for ecosystem disservices of urban green spaces. Urban Forestry \& Urban Greening; 18, 117-125.

Baldwin RW, Koehler PG, Pereira RM and Oi FM (2008) Public perceptions of pest problems. American Entomologist; 54 (2): 73-79.

Ballouard JM, Provost G, Barre D and Bonnet X (2012) Influence of a field trip on the attitude of schoolchildren toward unpopular organisms: An experience with snakes. Journal of Herpetology; 46 (3): 423-428.

Baltoń K (2015) Package "Mumin". [Online], https://cran.r-project.org/web/ packages/MuMIn/MuMIn.pdf, accessed 18 April 2017.

Bixler RD and Floyd MF (1997) Nature is scary, disgusting, and uncomfortable. Environment and Behavior; 29 (4): 443-467.

Bixler RD, Floyd MF and Hammitt WE (2002) Environmental socializationQuantitative tests of the childhood play hypothesis. Environment and Behavior; 34 (6): 795-818.

Bjerke T and Østdahl T (2004) Animal-related attitudes and activities in an urban population. Anthrozoos; 17 (2): 109-129.

Bjerke T, Kaltenborn BP and Odegardstuen TS (2001) Animal-related activities and appreciation of animals among children and adolescents. Anthrozoos; 14 (2): 86-94.

Butler JS, Shanahan J and Decker DJ (2003) Public attitudes toward wildlife are changing: A trend analysis of New York residents. Wildlife Society Bulletin; 31 (4): 1027-1036.

CBD. (2012) Cities and Biodiversity Outlook. Convention on Biological Diversity: Montreal, Canada.

Chawla L (1999) Life paths into effective environmental action. The Journal of Environmental Education; 31 (1): 15-26.

Chawla L and Derr V (2012) The development of conservation behaviors in childhood and youth. In: Clayton SD (ed). The Oxford Handbook of Environmental and Conservation Psychology. Oxford University Press: New York, pp 527-555.

Chipeniuk R (1995) Childhood foraging as a means of acquiring competent human cognition about biodiversity. Environment and Behavior; 27 (4): 490-512.

De Oliveira JAP et al. (2011) Cities and biodiversity: Perspectives and governance challenges for implementing the convention on biological diversity (CBD) at the city level. Biological Conservation; 144 (5): 1302-1313.

Dearborn DC and Kark S (2010) Motivations for conserving urban biodiversity. Conservation Biology; 24 (2): 432-440.

Dickman AJ (2010) Complexities of conflict: The importance of considering social factors for effectively resolving human-wildlife conflict. Animal Conservation; 13 (5): 458-466.

Eagles PFJ and Muffitt S (1990) An analysis of children's attitudes toward animals. The Journal of Environmental Education; 21 (3): 41-44.

Eriksson M, Sandstrom C and Ericsson G (2015) Direct experience and attitude change towards bears and wolves. Wildlife Biology; 21 (3): 131-137.

Freckleton RP (2011) Dealing with collinearity in behavioural and ecological data: Model averaging and the problems of measurement error. Behavioral Ecology and Sociobiology; 65 (1): 91-101.

Fábos JG and Ryan RL (2004) International greenway planning: An introduction. Landscape and Urban Planning; 68 (2-3): 143-146.

Goddard MA, Dougill AJ and Benton TG (2010) Scaling up from gardens: Biodiversity conservation in urban environments. Trends in Ecology \& Evolution; 25 (2): 90-98.

Hogue CL (1987) Cultural entomology. Annual Review of Entomology; 32, 181-199.

Hosaka T and Numata S (2016) Spatiotemporal dynamics of urban green spaces and human-wildlife conflicts in Tokyo. Scientific Reports; 6, 30911.

Hosaka T, Kurimoto M and Numata S (2016) An overview of insect-related events in modern Japan: Their extent and characteristics. American Entomologist; 62 (4): 228-234.

Hosaka T, Sugimoto K and Numata S (2017) Effects of childhood experience with nature on tolerance of urban residents toward hornets and wild boars in Japan. PLOS ONE; 12, e0175243.

Hudenko HW, Siemer WF and Decker DJ (2010) Urban carnivore conservation and management: The human dimension. In: Gehrt SD, Riley SPD and Cypher
BL (eds). Urban Carnivores: Ecology, Conflict, and Conservation. The Johns Hopkis University Press: Baltimore, pp 21-33.

Inskip C, Carter N, Riley S, Roberts T and MacMillan D (2016) Toward humancarnivore coexistence: Understanding tolerance for tigers in Bangladesh. PLoS ONE; 11, e0145913.

Kamihogi A (2009) Town Development Based on Local Ecology. Gakugeishuppansha: Kyoto, Japan, in Japanese.

Kansky R and Knight AT (2014) Key factors driving attitudes towards large mammals in conflict with humans. Biological Conservation; 179, 93-105.

Kawahara AY (2007) Thirty-foot telescopic nets, bug collecting video games, and beetle pets: Entomology in modern Japan. American Entomologist; 53 (3) 160-172.

Kawahara AY and Pyle RM (2013) An appreciation for the natural world through collecting, owing and observing insects. In: Lemelin RH (ed). The Management of Insects in Recreation and Tourism. Cambridge University Press: New York, NY, pp 138-152.

Kellert SR (1980) American-attitudes toward and knowledge of animals-an update International Journal for the Study of Animal Problems; 1 (2): 87-119.

Kellert SR (1993) Values and perceptions of invertebrates. Conservation Biology; 7 (4): 845-855.

Kellert SR (1996) The Value of Life. Island Press: Washington, D. C.

Kellert SR and Wilson EO (1993) The Biophilia Hypothesis. Island Press: Washington, D. C.

Lekies KS and Beery TH (2013) Everyone needs a rock: Collecting items from nature in childhood. Children, Youth and Environments; 23 (3): 66-88.

Lekies KS and Brensinger JD (2015) Childhood nature experience across residential settings: Rural, suburban, and urban. Risk, Protection, Provision and Policy, Geographies of Children and Young People; 12, 1-20.

Lemelin RH (2013) The Managenemt of Insects in Recreation and Toursim. Cambridge University Press: New York, NY.

MOE. (2016) Information on municipalities that have established local biodiversity act. [Online], http://www.biodic.go.jp/biodiversity/activity/local_gov/local/infor mation.html, accessed 18 April 2017. (in Japanese).

Macromill. (2013) A Survey on Lifestyle of Macromill Monitors. Macromill Inc. Tokyo.

Martín-López B, Montes C and Benayas J (2007) The non-economic motives behind the willingness to pay for biodiversity conservation. Biological Conservation; 139 (1-2): 67-82.

Miller JR (2005) Biodiversity conservation and the extinction of experience. Trends in Ecology \& Evolution; 20 (8): 430-434.

Miller JR and Hobbs RJ (2002) Conservation where people live and work Conservation Biology; 16 (2): 330-337.

Nabhan GP and St. Antoine S (1993) The loss of floral and faunal story: The extinction of experience. In: Kellert SR and Wison EO (eds). The Biophilia Hypothesis. Island Press: Washington, D. C, pp 229-250.

Nakamura M (2007) Vespa: Urban Invasion and Survival Strategy. Yasakashobo: Tokyo, in Japanese.

New TR (2013) The entomological and recreational aspects of interacting with Lepidoptera. In: Lemelin RH (ed). The Management of Insects in Recreation and Tourism. Cambridge University Press: New York, NY, pp 95-107.

Nomura S (2000) Protection of insects and policies. In: Baba K and Hirashima Y (eds). Science of Insect Collecting: New Edition. Kyushu University Press: Fukuoka, Japan, pp 133-260.

Revelle W (2016) Package "psych". [online], https://cran.r-project.org/web/ packages/psych/psych.pdf, accessed 18 April 2017

Sakurai R, Jacobson SK and Ueda G (2014) Public perceptions of significant wildlife in Hyogo, Japan. Human Dimensions of Wildlife; 19 (1): 88-95.

Sawaki M and Kamihogi A (1995) Study on the residents' taste for coexisting with nature life in the new town. Journal of the Japanese Institute of Landscape Architecture; 58 (5): 133-136, in Japanese.

Schlegel J and Rupf R (2010) Attitudes towards potential animal flagship species in nature conservation: A survey among students of different educational institutions. Journal for Nature Conservation; 18 (4): 278-290.

Shwartz A, Turbé A, Julliard R, Simon L and Prévot AC (2014) Outstanding challenges for urban conservation research and action. Global Environmental Change-Human and Policy Dimensions; 28, 39-49.

Siemer WF, Hart PS, Decker DJ and Shanahan JE (2009) Factors that influence concern about human-black bear interactions in residential settings. Human Dimensions of Wildlife; 14 (3): 185-197.

Simaika JP and Samways MJ (2010) Biophilia as a universal ethic for conserving biodiversity. Conservation Biology; 24 (3): 903-906.

Skandrani Z and Prévot AC (2015) Beyond green-planning political orientations: Contrasted public policies and their relevance to nature perceptions in two European capitals. Environmental Science \& Policy; 52, 140-149.

Soga M and Gaston KJ (2016) Extinction of experience: The loss of human-nature interactions. Frontiers in Ecology and the Environment; 14 (2): 94-101.

Soga M, Gaston K, Yamaura Y, Kurisu K and Hanaki K (2016) Both direct and vicarious experiences of nature affect children's willingness to conserve 
biodiversity. International Journal of Environmental Research and Public Health; 13 (6): 529.

Sonoda Y and Kuramoto N (2004) Residents' consciousness to the coexistence with wild mammals and the management of habitat environments in urban area. Journal of the Japanese Institute of Landscape Architecture; 67 (5): 779-784.

Soulsbury CD and White PCL (2015) Human-wildlife interactions in urban areas: A review of conflicts, benefits and opportunities. Wildlife Research; 42 (7): 541-553.

Tokyo Metropolitan Government. (2012) TOKYO GREEN PLAN2012-City Biodiversity Strategy-. [online], http://www.kankyo.metro.tokyo.jp/en/green ery/biodiversity.html, accessed 18 April 2017.

Tokyo Metropolitan Government. (2014) A result of a 2013 survey on percentage of green space areas in Tokyo. [online], http://www.metro.tokyo.jp/INET/ CHOUSA/2014/09/60o9t300.htm, accessed 18 April 2017. (in Japanese).

UN. (2014) Population Facts No 2014/2 A World of Cities. [online], http://www. un.org/en/development/desa/population/publications/pdf/popfacts/PopFacts_ 2014-2.pdf, accessed 18 April 2017.

van der Ploeg J, Caulian-Cureg M, van Weerd M and de Groot WT (2011) Assessing the effectiveness of environmental education: mobilizing public support for Philippine crocodile conservation. Conservation Letters; 4 (4): 313-323.

Wells NM and Lekies KS (2006) Nature and the life course: Pathways from childhood nature experiences to adult environmentalism. Chidren, Youth and Environments; 16 (1): 1-24.

Williams NSG, Lundholm J and Macivor JS (2014) Do green roofs help urban biodiversity conservation? Journal of Applied Ecology; 51 (6): 1643-1649.

Zhang WZ, Goodale E and Chen J (2014) How contact with nature affects children's biophilia, biophobia and conservation attitude in China. Biological Conservation; 177, 109-116.

\section{Data availability}

All data generated or analysed during this study are included in Supplementary Table S2.

\section{Additional information}

Supplementary Information: accompanies this paper at http://www.palgrave-journals .com/palcomms

Competing interests: The authors declare that they have no competing financial interests

Reprints and permission information is available at http://www.palgrave-journals.com/ pal/authors/rights_and_permissions.html

How to cite this article: Hosaka T, Sugimoto K and Numata S (2017) Childhood experience of nature influences the willingness to coexist with biodiversity in cities. Palgrave Communications. 3:17071 doi: 10.1057/palcomms.2017.71.

Publisher's note: Springer Nature remains neutral with regard to jurisdictional claims in published maps and institutional affiliations.

\section{(c) (i)}

This work is licensed under a Creative Commons Attribution 4.0 International License. The images or other third party material in this article are included in the article's Creative Commons license, unless indicated otherwise in the credit line; if the material is not included under the Creative Commons license, users will need to obtain permission from the license holder to reproduce the material. To view a copy of this license, visit http://creativecommons.org/licenses/by/4.0/

(C) The Author(s) 2017 